\title{
Towards an Integrative Framework of Conflict-handling Behaviour Integrating Western and Chinese Perspectives
}

Li, Xin; Worm, Verner; Xie, Peihong

\author{
Document Version \\ Accepted author manuscript \\ Published in: \\ Asia Pacific Business Review \\ DOI: \\ 10.1080/13602381.2017.1357322 \\ Publication date: \\ 2018 \\ License \\ Unspecified
}

Citation for published version (APA):

Li, X., Worm, V., \& Xie, P. (2018). Towards an Integrative Framework of Conflict-handling Behaviour: Integrating Western and Chinese Perspectives. Asia Pacific Business Review, 24(1), 22-36.

https://doi.org/10.1080/13602381.2017.1357322

Link to publication in CBS Research Portal

\section{General rights}

Copyright and moral rights for the publications made accessible in the public portal are retained by the authors and/or other copyright owners and it is a condition of accessing publications that users recognise and abide by the legal requirements associated with these rights.

\section{Take down policy}

If you believe that this document breaches copyright please contact us (research.lib@cbs.dk) providing details, and we will remove access to the work immediately and investigate your claim.

Download date: 26. Apr. 2023

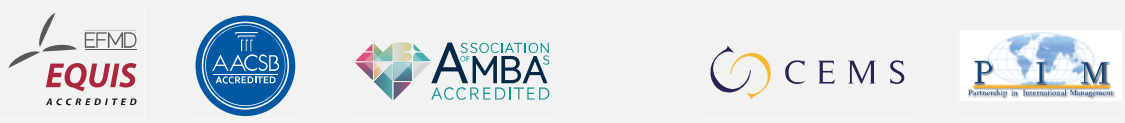




\title{
Towards an Integrative Framework of Conflict-handling Behaviour: Integrating Western and Chinese Perspectives
}

\author{
Kin Li, Verner Worm, and Peihong Kie \\ Journal article (Accepted version)
}

Cite: Li, X., Worm, V., \& Xie, P. (2018). Towards an Integrative Framework of Conflict-handling Behaviour: Integrating Western and Chinese Perspectives. Asia Pacific Business Review, 241), 22-36. DOl: 10.1080/13602381.2017.1357322

This is an Accepted Manuscript of an article published by Taylor \& Francis in Asia Pacific Business Review on 31 Jul 2017, available online:

http://www.tandfonline.com/10.1080/13602381.2017.1357322

Uploaded to CBS Research Portal: January २०19 


\title{
Towards an integrative framework of conflict-handling
}

\author{
behaviour: Integrating Western and Chinese
}

perspectives

Xin $\underline{\operatorname{Li}}$ (corresponding author),

Copenhagen Business School, Denmark.

$\underline{\text { xl.int@ } @ \text { cbs.dk }}$

Verner Worm

Copenhagen Business School, Denmark.

$\underline{\text { vw.int @ cbs.dk }}$

Peihong $\underline{\text { Xie }}$

Shanghai University of International Business and Economics, China.

phxie68@suibe.edu.cn 


\begin{abstract}
Following in the footsteps of Frances Brew and the late Kwok Leung (1958-2015), we attempt to further integrate the Western dual-concern model of conflict and the Chinese dual-motive model of harmony. Our integrative framework of conflict-handling behaviour is designed to be more comprehensive in its coverage of conflict-handling styles than the integrative model developed by Brew in 2007, and more symmetric in its treatment of the Western and Chinese perspectives than the integrative model jointly developed by Leung and Brew in 2009. In developing our alternative integrative model, we try to take a further step in the process of universalization of an indigenous Chinese theory.
\end{abstract}

Keywords: China: Chinese; conflict; integration; indigenous; universal; Western.

\title{
Acknowledgement:
}

\section{This research was partially supported by the Shanghai Summit and}

\author{
Plateau discipline project, China, PRC.
}




\title{
Towards an integrative framework of conflict-handling behaviour:
}

\section{Integrating Western and Chinese perspectives}

\begin{abstract}
Following in the footsteps of Frances Brew and the late Kwok Leung (1958-2015), we attempt to further integrate the Western dual-concern model of conflict and the Chinese dual-motive model of harmony. Our integrative framework of conflict-handling behaviour is designed to be more comprehensive in its coverage of conflict-handling styles than the integrative model developed by Brew in 2007, and more symmetric in its treatment of the Western and Chinese perspectives than the integrative model jointly developed by Leung and Brew in 2009. In developing our alternative integrative model, we try to take a further step in the process of universalization of an indigenous Chinese theory.
\end{abstract}

Keywords: China; Chinese; conflict; integration; indigenous; universal; Western. 


\section{Introduction}

It is well acknowledged that in a globalised world there is a need to develop additional management theories that are more globally oriented. In particular, developing new globally oriented conflict management theories becomes important as people with different worldviews and cultural values need to overcome possible challenges and obstacles in communication and negotiation. One of the scholars contributing most to this endeavour, by integrating Chinese theories with existing Western theories, is the late Professor Kwok Leung (1957-2015).

Seeing that the most influential Western theory of conflict handling styles, i.e., the dual-concern model (e.g., Rahim, 1983), focuses exclusively on the outcome of conflict, and realizing that in the Chinese context people care a lot about harmony in interpersonal relationships, Leung first developed an alternative Chinese model of conflict style by focusing on harmony in interpersonal relationships (Leung, Koch, and Lu, 2002); he then integrated it with the Western dual-concern model to propose an integrative model of conflict styles (Leung and Brew, 2009). In their integrative model, Leung and Brew retained the two dimensions of the Chinese harmony-based model, while reducing the two dimensions of the western dual-concern model to a single one with an adapted label. Such an asymmetry in treating the Western and Chinese models in their approach to integration is one of the two deficiencies of Leung and Brew's integrative model. The second deficiency of Leung and Brew's (2009) integrative model is that if the five conflict styles identified in the Western dual-concern model are supplemented by the four specified in the Chinese dualmotive model, there are nine identified styles-which means that Leung and Brew's (2009) integrated model with its eight identified styles does not cover all the possibilities offered by the two-base model. 
Towards an integrative framework of conflict-handling behaviour Submitted to APBR, 19 April 2017

Revised \& Resubmitted, 23 June 2017 Final revision, 11 July 2017

The two deficiencies of Leung and Brew's integrative model are interlinked. Due to their reduction of the two theoretical models' four dimensions combined to three dimensions, they eventually set a limit on the coverage of possible conflict styles for their three-dimensional integrative model; namely, their $2 \times 2 \times 2$ model can only cover eight possible conflict styles. We see these two deficiencies as problems in existing literature, which motivates us to develop a better-designed integrative model of conflict handling behaviours.

Methodologically, there are four components in our approach to integration above and beyond Leung's and Brew's. First, we follow Brew's (2007) symmetric approach to integrating Western and Chinese models, i.e. treating both models symmetrically; and more specifically, we retain both dimensions of each of the two models, which results in a preliminary two-dimensional $4 \times 4$ integrative model. Second, recognising that there might be overlaps or redundancies among the 16 possible combinations within the 4 × 4 matrix, we eliminate some of the 16 combinative possibilities if they are redundant or do not make sense. After eliminating those styles, nine styles of conflict handling behaviour remain in a $3 \times 3$ model finally resulted. Third, we focus on whose interest is actually served in the outcome of conflict. Fourth, wherever possible, we associate the nine remaining styles with the existing styles identified in the Western dual-concern models and the Chinese harmony-based model by directly adopting the existing labels in our newly proposed integrative model.

\section{Research Questions}

We now go on to ask two major research questions. One research question is how do we redress the 'asymmetry' problem? The second is how do we further develop Leung's and Brew's (2009) model into a more 'integrative and generic framework' of conflict-handling behavior? 
In what follows, we first review and critique the Western literature on the dual-concern model of conflict; then we introduce the Chinese dual-motive model of harmony pioneered by Leung. Next, two attempts to integrate the Chinese and Western models will be explained and critiqued. Afterwards, we propose our alternative integrative framework of conflict-handling behaviour that identifies nine styles placed in a two-dimensional 3 x 3 matrix. We conclude the paper by first suggesting some directions for future empirical studies based on our proposed integrative framework, and then discussing the value and relevance of the dynamic interplay approach to universal theory building proposed and practiced by Kwok Leung for future Chinese indigenous management research.

\section{Literature Review}

\section{The Western dual-concern model of conflict}

Conflict in Western tradition has been defined in many ways. Here we use Thomas' (1976: 891) definition that 'conflict is the process which begins when one party perceives that the other party has frustrated, or is about to frustrate, some concern of his'. Conflict-handling behaviours have been classified by various schemes that are either uni-dimensional (Deutsch, 1949, 1973, 2000) or twodimensional (Blake and Mouton, 1964; Filley, 1975; Thomas, 1976; Pruitt, 1983; Rahim, 1983). The two-dimensional dual-concern model is probably 'the most influential conflict framework' in the West and beyond (Leung and Brew (2009: 412). It plots multiple conflict-handling behaviours on a single chart with two dimensions: concern for self and concern for others (Rahim and Bonoma, 1979; Thomas, 1976). The dual-concern model identifies five distinct conflict-handling styles. While different scholars use different labels, these five styles are essentially dominating, obliging, avoiding, integrating, and compromising. 
Towards an integrative framework of conflict-handling behaviour

Submitted to APBR, 19 April 2017

Revised \& Resubmitted, 23 June 2017

Final revision, 11 July 2017

The dominating style refers to the conflict-handling behaviour that is high on concern for self and low on concern for others. In contrast, the obliging style is low on concern for self and high on concern for others. The avoiding style is low on both concern for self and concern for others. In contrast, the integrating style is high on both concern for self and concern for others. The compromising style is moderate on both concern for self and concern for others.

An embryonic version of this five-style scheme of conflict management was initially described and developed by Follet (1940/1926) who identified three primary styles to handle conflict, i.e. domination, compromise, and integration, and two secondary styles, i.e. avoidance and suppression. It is Blake and Mouton (1964) who are the first to present a two-dimensional 'managerial grid' to explain how managers deal with management-employee relationships involving conflict behaviour. The two dimensions of their managerial grid are concern for production of results and concern for people. Later, Blake and Mouton (1970) relabeled their managerial grid into the conflict grid, and therefore extended the grid's explanatory power from managerial conflicts to all social conflicts. To visualise each style's relative emphasis on each of the two dimensions, they plot the five styles on a grid or matrix with a nine-point scale on each dimension.

Filley (1975) assigns a win-lose score to each of the five different styles. The dominating style is called the 'win-lose style' adopted by 'the tough battler'; the yielding style is called the 'yield-lose' style of 'the friendly helper'; and the avoiding style is called the 'lose-leave' style. He also uses the labels of integrative style of 'the problem solver' and 'compromise style'. Following Blake and Mouton (1970), Filley also adopts a nine-point scale system for his two dimensions (labelled concern for personal goals and concern for relationship).

Thomas (1976) compares and contrasts the uni-dimensional or dichotomous scheme pioneered by Deutsch $(1949,1973)$. He sees the simplicity of the dichotomous scheme appealing, but points out 
that it 'appears to greatly oversimplify the more complex range of options available to the conflict party', which causes unnecessary confusion (Thomas, 1976: 901). He labels the two dimensions as cooperativeness (i.e. desire to satisfy the other's concerns) and assertiveness (i.e. desire to satisfy one's own concern).

What is interesting and useful for our purposes here is that Thomas (1976: 898-899) identifies four patterns of conceptualization of conflict: either/or, zero-sum, indeterminate and unresolvable. As Thomas acknowledges, the zero-sum conceptualization is similar to (but less extreme than) the either/or pattern. The indeterminate conceptualization 'is apt to be the result of defining the issue in terms of the underlying concerns of the two parties' (p. 899), and therefore it can be labelled as a 'both/and' pattern. In the unresolvable conceptualization, the conflict is 'depicted as frustrating to both parties' and 'neither party is seen as gaining at the other's expense' (p. 899); therefore, it can be labelled as a 'neither/nor' pattern. Horney's (1945, cited in Thomas, 1976: 901) categorization of interpersonal behaviour into movement against, toward, and away from the other appears to correspond with the either/or, both/and, and neither/nor conceptualizations.

Building a scheme similar to Blake and Mouton's (1964) and Thomas' (1976), Rahim and Bonoma (1979) rename the two dimensions as 'concern for self' and 'concern for others'. They label the five styles as dominating, obliging, avoiding, compromising, and integrating. After Rahim (1983: 375) provided evidence of empirical validity of the five 'a priori' conflict styles (cf. De Dreu et al., 2001), their version of the dual-concern model has become the most widely used conflict-handling style framework ${ }^{1}$, which appears in the latest textbook on conflict and negotiation (e.g. Lewicki et al. 2016).

\footnotetext{
${ }^{1}$ Some scholars deviate a little bit from this five-style approach. Pruitt (1983) accepts all of the five except the compromising style. Van de Vliert \& Euwema (1994: 674), based on Bales's (1950) agreeableness and activeness as common factors of modes and taxonomies of conflict behavior, identify six different conflict styles, i.e. 'avoiding, accommodating, compromising, problem solving, indirect fighting, and two forms of direct fighting-issue fighting and outcome fighting'.
} 
Towards an integrative framework of conflict-handling behaviour

Submitted to APBR, 19 April 2017

Revised \& Resubmitted, 23 June 2017 Final revision, 11 July 2017

Despite its wide acceptance, the dual-concern model has two largely neglected deficiencies. The first is that there are five conflict styles placed on a $2 \times 2$ matrix, with the compromising style being placed in the centre of the matrix 'due to a moderate concern about self and other' (Pruitt, 1983: 172). Designed this way, each dimension is essentially divided into three broad ranges of value low, moderate, and high. Mathematically speaking, the division of each dimension into three value ranges results in nine possible combinations, rather than the five identified combinations. This may explain why Pruitt (1983: 173) chose to exclude 'compromising' from his version of the 2 x 2 dualconcern model with the following rationale: 'This [compromising] approach is not taken in the present article because compromises are seen as arising from lazy problem solving involving a halfhearted attempt to satisfy both parties' interests. In other words, it seems unnecessary to postulate a separate strategy to explain the development of compromises'. At any rate, the dual-concern model and its list of five conflict-handling styles are unlikely to be exhaustive.

The second deficiency is that the situation of 'low concern for both self and other' is much more complex than a unitary label such as 'avoiding' can capture. For example, Pruitt (1983: 172) uses 'inaction' instead of 'avoiding' and explains that 'Inaction wastes time and sometimes even temporarily suspends the negotiation. This, of course, tends to delay agreement and can even contribute to a negotiation breakdown if it leads the other party to become discouraged and break off.' Conceptually, we can identify three types of low/low or neither/nor style: (1) one may prevent conflict from happening by proactively avoiding entering into a conflict situation; (2) once a conflict appears, one can no longer avoid it but must respond to it, although one may still try to sidestep or withdraw from the conflict or passively delay the resolution; and, (3) one may engage in mutually destructive behaviour by preventing the other from winning even at one's own cost. Therefore, the 'low concern for both self and other' situation needs to be treated in a more nuanced manner. 


\section{Kwok Leung's dual-motive model of harmony}

In 1984, Kwok Leung published an article with Michael Bond entitled 'The impact of cultural collectivism on reward allocation', which is based on Leung's same-titled Master's thesis submitted to the Graduate College at the University of Illinois at Urbana-Champaign. As can be seen from the thesis title, cultural issues in general (and collectivism in particular) was one of the core research topics in Leung's scholarship right from the beginning. As the issue of reward allocation comes close to conflict management because it is about distribution of scarce resources among people who compete, one may imagine, but not know with certainty, that this early research created a background for Leung's later interest in (and contribution to) cross-cultural conflict-management research.

The main findings of Leung and Bond (1984) - which are well-known today but little-known at that time -are that the Chinese use equity norm in their reward allocation with strangers and equality norm with friends. What is more interesting is that the collectivistic Chinese were found to follow the equity norm more closely in dividing the group reward than the individualist American subjects when the chance to meet again was non-existent or small. The results are entirely consistent with the notion that collectivists are oriented toward interpersonal harmony in well-defined in-groups and behave in sharply different ways toward out-group members.

In line with expectancy theory (Atkinson, 1964; Vroom, 1964), Leung (1987) argued that animosity reduction is an important goal in conflict handling in Chinese society; he proved empirically that collectivistic Chinese subjects prefer bargaining and mediation as opposed to adjudicatory procedures to a larger extent than did the individualistic American subjects. The reason for the Chinese subjects' procedural preference was that they perceived mediation and bargaining as more 
Towards an integrative framework of conflict-handling behaviour

Submitted to APBR, 19 April 2017

Revised \& Resubmitted, 23 June 2017

Final revision, 11 July 2017

capable of reducing the animosity between the disputants, whereas adjudication was perceived as less capable because it binds parties to a resolution.

Realizing that the aforementioned difference in procedural preferences between Chinese and Americans may be caused by some East-West differences other than collectivism and individualism, Leung et al. (1992) designed a study to resolve this ambiguity by comparing two collectivist societies: one from the West (Spain) and the other from the East (Japan). The results are consistent with Leung's (1987), which confirms the argument that expectancies based on process control and animosity reduction are culture-general predictors of procedural preference. What is important for the development of Leung's indigenous dual-motive model of interpersonal harmony is that in Leung et al. (1992) the notion 'harmony-enhancing' is used along with that of animosity reduction.

Later, Leung (1997) realised that animosity reduction becomes a major concern only in disputes of high intensity, and in many everyday conflicts animosity may be relatively low. In such situations, a psychological process different than animosity reduction may take place. To overcome the shortcomings of the notion of animosity reduction, Leung (1997) proposed a new concept of disintegration avoidance to explain the conflict-handling strategies of collectivists in situations of mild conflict. The seed of the development of this new concept may have been planted already back in 1988.

Seeing that most conflict resolution research had ignored the strategy of conflict avoidance, Leung (1988) designed a study to examine the determinants of the occurrence of conflict avoidance in a collectivist society (Hong Kong) and an individualist society (U.S.). He identified two major determinants of conflict avoidance: the severity of the conflict (whether the stakes involved are large or small) and the relationship between the would-be disputants (whether they are in-group or 
Towards an integrative framework of conflict-handling behaviour

Submitted to APBR, 19 April 2017

Revised \& Resubmitted, 23 June 2017

Final revision, 11 July 2017

out-group members). His finding is fully consistent with previous conceptualizations of cultural collectivism.

Leung (1997: 644) defines disintegration avoidance as 'avoiding actions that will strain a relationship and lead to its weakening and dissolving' and harmony enhancement as 'engaging in behaviors presumed to strengthen the relationships among the interactants'. While prior crosscultural literature treated in-group harmony as a unitary concept, Leung's distinction between disintegration avoidance and harmony enhancement is a powerful tool that can be used to explain the conflict behaviour of collectivists.

While Leung (1997) used disintegration avoidance and harmony enhancement as a dichotomy or continuum, he and his colleagues (Leung, Koch, and Lu, 2002) further developed this distinction into a two-dimensional, dual-motive model of interpersonal harmony. What triggered this theoretical development was their review of the classical Confucian doctrines from which they found no encouragement of conflict avoidance. Quite to their surprise, the classical Confucian notion of harmony does embody disagreement and open debate. They then realised that harmony as conflict avoidance is not a main feature of classical Confucianism, but instead a widely adopted practice of the secular cultural collectivism (see Warner, 2014). Based on their review of several indigenous theories involving the notion of harmony, they argue that harmony-seeking behaviour can be motivated by an instrumental as well as a value motive. This two motives are associated respectively with disintegration avoidance and harmony enhancement. They adopt these two distinct motives for harmony as two independent dimensions, to form a 2 x 2 typology that identifies four types of harmony-seeking behaviours: aligning, disintegrating, smoothing, and balancing. Leung et al.’s (2002) indigenous dual-motive model of harmony functions as a counterpart to the Western dual-concern model of conflict. The two models provide the raw 
materials for future integration (Leung and Brew, 2009), the next step in the dynamic interplay process of developing a universal theoretical framework (see Rowley, 2016).

\section{Two attempts to integrate the dual-concern model and dual-motive model}

Brew (2007) was the first to integrate the Western dual-concern model of conflict and the Chinese dual-motive model of harmony. The motivation for her attempt to integrate the two models is her realization that 'social relationships are equally important in the Western world as in Asia, even if underlying motivations might differ' and therefore 'Perhaps the need for harmonious relationships as a motivator for some conflict management behavior has been overlooked in Western theories' (p. 46). Recognizing that people of any culture are likely to be caught in the tension between 'assertive conflict to achieve self-directed goals and maintaining harmony to protect the relationship' (p. 46), Brew posits that 'the harmony and conflict dichotomy is reflective of the famous yang and yin principle' (p. 47, italics in original).

Despite the fact that Thomas (1976) explicitly expresses his preference for a two-dimensional approach to the dichotomous approach based on Deutsch's (1949) theory of cooperation and competition, Brew (2007: 47) points out that Deutsch's dichotomy of cooperation and competition 'has also been reflected in the popular grid models of Thomas and Kilmann, 1974 (high versus low cooperation was crossed with high versus low assertiveness) and Rahim, 1983 (high versus low concern for self was crossed with high versus low concern for others)'. In developing her integrative 'Yin and Yang model of conflict management' (Brew, 2007: 49), Brew chooses to represent the two dimensions of the Western dual-concern model of conflict by one single dimension underpinned by Deutsch's dichotomy, though with a different label, i.e. 'the harmony and conflict dichotomy' (p. 47). 
Towards an integrative framework of conflict-handling behaviour

Submitted to APBR, 19 April 2017

Revised \& Resubmitted, 23 June 2017

Final revision, 11 July 2017

Likewise, Brew chooses to represent the two dimensions of Leung et al.'s (2002) dual-motive model of harmony by a single dimension dichotomised into harmony as instrumentality vs. harmony as value. Therefore, Brew essentially changed the more advanced framework of Leung et al. (2002) back to Leung's (1997) original dichotomy of disintegration avoidance and harmony enhancement. When the two dimensions (representing the Western and Chinese models, respectively) are crossed, four distinct conflict styles are identified: constructive controversy, destructive confrontation, constructive diplomacy, and smoothing.

While Brew's (2007) work provides an innovative approach to integrating the Western and Chinese perspectives, her framework with four identified conflict styles is not comprehensive enough to cover all possible conflict-handling strategies included in the two base models. For example, the compromising style of the Western dual-concern model is incorporated in her model. To redress this small coverage problem of Brew (2007), Leung and Brew (2009) propose an enlargement of Brew's (2007) model in order to encompass the best insights from both perspectives.

What Leung and Brew (2009) did was twofold:, on the one hand, they restore the harmony as instrument vs. harmony as value dimension used in Brew (2007) back into two independent dimensions as treated in Leung et al. (2002); on the other hand, they change the cooperation (harmony) vs. competition (conflict) dimension of Brew's (2007) model into the third dimension 'importance of personal goal' (p. 417) with high vs. low as its two values. Leung and Brew (2009: 417) rename the first two restored dimensions as 'concern for intrinsic worth of relationship' with high harmony enhancement vs. low harmony enhancement as its two values, and 'need for relational benefits for self' with high disintegration avoidance vs. low disintegration avoidance as its two values. Their third dimension 'importance of personal goal' is explicitly linked to the 'concern for self' dimension of the dual-concern model. With these three dimensions, Leung and Brew (2009) specify eight different conflict styles: constructive diplomacy, accommodating, 
Towards an integrative framework of conflict-handling behaviour

Submitted to APBR, 19 April 2017

Revised \& Resubmitted, 23 June 2017

Final revision, 11 July 2017

constructive controversy, concessional obliging, superficial compliance, avoiding, destructive confrontation, and ignoring.

Comparing Brew (2007) and Leung and Brew (2009), the two integrative models have their own merits and shortcomings. Interestingly, one's strength is the other's shortcoming, and vice versa. While Leung and Brew's (2009) model is more comprehensive in coverage than Brew's (2007) model, Brew's model is more symmetric and equal in treating the Western and Chinese perspectives than Leung and Brew's model. The asymmetry in treating the Western and Chinese perspectives, in our view, is one of the two deficiencies of Leung and Brew's integrated model, although their model has been the best available integration to date.

Due to their exclusion of the concern for others dimension of the Western dual-concern model, they set a limit on the coverage of possible conflict styles for their three-dimensional 2 × 2 × 2 modelnamely, their model can only cover eight possible conflict styles. However, as Leung et al. (2002: 211) explicitly acknowledge, their indigenous dual-motive model is distinctly designed from the Western dual-concern model because their model is 'group-level' and relationship-based, whereas the dual-concern model is 'individual-level, outcome-based'. They also explicitly state that their model 'is not to replace the dual concern model, but to supplement it'. Accordingly, if the five conflict styles identified in the dual-concern model are supplemented by the four styles specified in the dual-motive model, there are nine styles. This means that Leung and Brew's (2009) integrated model with its eight symmetric and equal identified styles does not cover all the possibilities offered by the two base models. This is the second deficiency of Leung and Brew's integrated model.

The two deficiencies of Leung and Brew's (2009) integrated model serve as the research gap that has motivated our present study. We attempt to further develop Leung's and Brew's model by redressing the asymmetry and incomprehensiveness deficiencies. In the next section, we explain our approach to, and the outcomes of, further integration. 


\section{An Integrative framework of conflict-handling behaviour}

\section{An approach to integration}

There are four integral components in our approach to integration.

First, we follow Brew's (2007) approach to integrate the Western and Chinese perspectives by a two-dimensional framework in which the Western dual-concern model of conflict is represented on the vertical axis and the Chinese dual-motive model of harmony is on the horizontal axis. We also follow Brew's approach to treat the Western and Chinese models symmetrically. Namely, we treat each model's two dimensions as equally important in the integration process, by taking into full consideration all the $2 \times 2$ possible combinations of each model: high/low, low/high, high/high, and low/low. If we term the four possible combinations as either/or type 1, either/or type 2, both/and, and neither/nor, respectively, and place them on both horizontal and vertical axes, then we can have an initially two-dimensional matrix with 4 x $4=16$ combination possibilities (see Figure 1).

\section{INSERT FIGURE 1 ABOUT HERE}

Second, we eliminate some of the 16 combinative possibilities because they are redundant or do not make sense. We recognise that there might be overlaps between the 16 combinations of the $4 \times 4$ matrix. For example, concern for others but not self may overlap with concern for self-coupled with taking harmony in relationship as either instrument or value. The reason is that concern for others may be that one sees intrinsic value in interpersonal harmony or an instrumental role in it. We also recognise that some combinations of the $2 \times 2$ matrix of the dual-concern model and dual-motive model may not make sense. For example, the combination of 'only concern for others but not self' and that of 'taking harmony in relationship as both instrument and value' can be viewed as 
Towards an integrative framework of conflict-handling behaviour

Submitted to APBR, 19 April 2017

Revised \& Resubmitted, 23 June 2017

Final revision, 11 July 2017

unreasonable or even impossible. Accordingly, we eliminate the overlaps and impossibilities by excluding the second row and the third column from consideration. In Figure 1, those cells marked with an ' $x$ ' symbol are eliminated. Therefore, instead of the initial 4 x $4=16$ possible combinative styles, we end up with nine possible conflict-handling styles.

Third, to overcome the confusion around the combination of 'low concern for both self and others' (as explained in the review of the dual-concern model), we shift our focus away from 'concern for whose interest' to 'whose interests are actually gained in the outcome of the conflict'. This shift of focus is theoretically justifiable because the Western dual-concern model is primarily an 'outcome'focused model (Gladwin and Walter, 1980: 55; Leung and Brew, 2002: 211). This shift also makes practical sense. According to Blake and Mouton's (1970: 418) conception, 'The phrase “concern for" does not show results produced but rather denotes the degree of emphasis in his thinking that the man places on getting results'. Following this conception, it is hard to imagine a situation in which one places little or no emphasis on thinking about getting results when handling a conflict. In contrast, if we shift our focus from 'concern for interest' to 'actual interest gained in the outcome', we can easily imagine a situation in which neither party's interest is served in the conflict's outcome if both parties adopt a mutually destructive conflict-handling style.

Fourth, wherever possible, we associate the nine remaining styles with the existing styles identified in the Western dual-concern models and the Chinese harmony-based model by directly adopting the existing labels in our newly proposed integrative model.

\section{Our two-dimensional $3 \times 3$ integrative framework}

A two-dimensional $3 \times 3$ matrix results from our aforementioned methodological approach (see Figure 2). The vertical dimension is named 'whose interests are served in the outcome' with three values: self (either/or), both (both/and), and none (neither/nor). The horizontal dimension is named 
'which role of relationship harmony is taken' with three values: instrumental (either/or, type 1), intrinsic (either/or, type 2), and irrelevant (neither/nor). The $3 \times 3$ matrix produces nine distinct styles of conflict handling.

\section{INSERT FIGURE 2 ABOUT HERE}

The first style is labelled 'favour-reciprocating' to denote that the focal party, albeit being selfconcerned, will voluntarily concede without asking the other party to do so in the current conflict (anticipating that the other party will reciprocate in another conflict in the future). This 'favourreciprocating' style corresponds to Rahim and Bonoma's (1979: 1327) notion of 'willing to give up something in exchange for getting something from the other in the future'.

The second style is labelled 'self-sacrificing' to denote that the focal party, albeit being selfconcerned, will voluntarily self-sacrifice because he or she places high significance on harmony in the relationship with the other party. This 'self-sacrificing' style corresponds to Thomas's (1976: 901) notion of 'self-sacrificing for the sake of their relationship'.

The third style is labelled 'egoic dominating' to denote that the focal party is extremely selfconcerned, without consideration of relationship harmony. It corresponds to the standard domination style of the dual-concern model.

The fourth style is labelled 'deceptive complying' to denote that the focal party has concern for both parties but treats relationship harmony as an instrument for advancing self-interests. With such an orientation, the focal party will try to maintain the face of the other party by not directly or publically confronting the other party, but he or she will try to pursue his or her own interests by not following what the other party has expected from him or her. This 'deceptive complying' style corresponds to Hwang's (1997-8) notion of 'agrees publicly and defies privately'. 
Towards an integrative framework of conflict-handling behaviour

Submitted to APBR, 19 April 2017

Revised \& Resubmitted, 23 June 2017

Final revision, 11 July 2017

The fifth style is labelled 'constructive balancing' to denote that the focal party has concern for both parties and treats relationship harmony as valuable. With such an orientation, the focal party may exhibit three types of behaviours in approaching conflict. First, he or she may try to satisfy both parties by resolving the conflict or solving the problem. Secondly, he or she may engage in openminded debate with the other party with confidence that such debate will not necessarily damage their relationship. Thirdly, he or she may choose to smooth the conflict in a diplomatic manner with the assumption that the other party, albeit having harmonious relationship with him or her does care about his or her face so that a diplomatic way of approaching the conflict is necessary. Therefore, this 'constructive balancing' style embraces three constructive and balanced styles: the problemsolving style of the Western dual-concern model the constructive controversy, and constructive diplomacy styles in Leung and Brew's (2009) model.

The sixth style is labelled 'mutual compromising' to denote that the focal party has concern for both parties, while having little or no consideration of relationship harmony as either instrument or value. Here, the focal party's primary concern is to get part of his or her demand met in the negotiation. To do so, he or she needs to ensure that the negotiation doesn't become deadlocked by voluntarily compromising something and expecting (or demanding) that the other party does the same. This 'mutual compromising' style corresponds to the compromising style of the dual-concern model. The seventh style is labelled 'passive delaying' to denote the situation in which, on the one hand, the focal party takes relationship harmony as instrument so that he or she will not directly confront the other party; on the other hand, because the focal party does not anticipate that his or her own concern will be satisfied in the conflict's outcome, he or she tries to passively delay the conflict's resolution. This style corresponds to Pruitt's (1983) 'inaction'. According to Pruitt (1983: 172), 'Inaction wastes time and sometimes even temporarily suspends the negotiation. This, of course, tends to delay agreement and can even contribute to a breakdown in the negotiation if it leads the 
other party to become discouraged and break off'. The outcome of this 'passive delaying' style is that neither party's concern will be satisfied.

The eighth style is labelled 'proactive avoiding' to denote the situation in which the focal party takes relationship harmony as value so that he or she will proactively prevent himself or herself and the other party from entering into a conflict situation by not insisting on his or her own concern and not letting the other party have the chance to insist on his or her concern. The outcome of this 'proactive avoiding' style is that the relationship harmony will not be affected on the one hand, yet on the other hand, neither party's potential concern will be satisfied.

The ninth style is labelled 'destructive confrontation' to denote that the focal party has little or no concern for the other party and does not consider relationship harmony at all, so he or she will try all means to prevent the other party from winning - even at his or her own expense. In plain language, the focal party's stance is that if he or she cannot win, then he or she will not let anyone else win. This style corresponds to Brew's (2007) and Leung and Brew's (2009) notion of 'destructive confrontation'.

\section{Discussion, Future Research and Implications}

Building on the integrative models of Brew (2007) and Leung and Brew (2009), we have proposed an alternative integrative framework of conflict-handling behaviour that is more comprehensive than Brew's (2007) model and more symmetric than Leung's and Brew’s (2009) model.

Despite this article's focus being on theory building, which is in itself is a legitimate and valuable academic endeavor (Redding 2017), it is necessary and important for the theoretical model proposed here to be tested empirically in the future. Here, we suggest some directions for future research: (1), to empirically test whether this framework and its nine styles correspond to reality, i.e., people's conflict handling styles in practice; (2), to empirically test the impacts of different 
Towards an integrative framework of conflict-handling behaviour

Submitted to APBR, 19 April 2017

Revised \& Resubmitted, 23 June 2017

Final revision, 11 July 2017

styles on the outcome of conflict; (3) to empirically test if there are some patterns that people from different cultures prefer some styles to others; (4), to empirically test whether people change their primary styles according to the change of conflict situation,; (5), to empirically test whether there is a developmental process in which people change their primary styles as they grow; (6), to empirically test whether cognitive or behavioral complexity has an impact on how people select or change their primary styles. In the absence of relevant empirical research, it is too early to tell if the integrative model proposed here is universally applicable or not.

Here, it is relevant to discuss the value and relevance of the dynamic interplay approach to universal theory building proposed and practiced by Kwok Leung for future Chinese indigenous management research..

For Leung, the value of indigenous social science research is without doubt. Leung, Wang, and Deng (2016: 110) point out that 'Practically speaking, indigenous research should generate the most appropriate solutions to local problem because the findings and the theories guiding the research are highly compatible with the phenomena under study'. They also posit, 'For argument's sake, Western psychological theories can be regarded as indigenous in nature, as the goal is to develop accurate understanding and prediction of the behaviours of individuals in the Western cultural context, but not the behaviours of people from non-Western cultures' (p. 111).

However, while the indigenous 'Western theories and findings are often assumed to generalise to other cultural contexts' (Leung et al., 2016: 111), 'indigenous research in non-Western cultures does not receive much attention from Western researchers, who tend to regard indigenous research and theories as irrelevant to their cultural contexts' (p. 110). Such an asymmetric perception is supported by the fact that, on the one hand, 'previous research has indeed demonstrated that many Western theories do perform reasonably well in non-Western contexts like China' (p. 111), and on the other hand, 'There is, of course, no Chinese management theory that enjoys such status [i.e. 
Towards an integrative framework of conflict-handling behaviour Submitted to APBR, 19 April 2017

Revised \& Resubmitted, 23 June 2017 Final revision, 11 July 2017

being rooted in Chinese cultural context but applicable to other cultural contexts] at this time' (Leung, 2009: 123).

Yet Leung (2009: 122) insists that 'there is no inherent reason why emic theories developed in the Chinese context (a Chinese theory of management) cannot become universal theories'. We strongly share Leung's argument. Leung et al. (2016) identify two broad approaches to globally relevant indigenous research: (1) the distinctive approach that develops 'unique and novel universal theories that are distinct from existing theories', and (2) the integrative approach in which 'indigenous findings and theories are integrated with relevant theories from the West for the development of both locally and globally relevant theories'. Leung et al. (2016: 113) contend that the integrative approach is 'much more prevalent than the distinctive approach because Western research has a long tradition, and it is natural to compare and contrast Chinese indigenous research with similar research originating from the West'. Such an integrative approach was also supported by Marshak (1993) who envisioned a unified theory of change that incorporating both the Western linear model and the Chinese cyclical model of change.

Leung et al. (2016: 120) identify three steps involved in the process of universalization of indigenous ideas and theories:

'First, a program of indigenous research is conducted, with the goal of providing more accurate understanding and prediction in the Chinese cultural context. A model or framework is developed based on such indigenous research. The second step involves testing this model or framework in diverse cultural contexts to assess its universality. Modification may be necessary to render a model or framework universal, and not all indigenous models or frameworks have universal applications around the world. The final step involves the integration of the indigenous model or framework with a relevant theory that is supposed to be universal.' 
Towards an integrative framework of conflict-handling behaviour Submitted to APBR, 19 April 2017

Revised \& Resubmitted, 23 June 2017 Final revision, 11 July 2017

It is clear that Leung himself has followed the three-step process in making his indigenous theory of harmony universal. His first step was to develop the dual-motive model of harmony (Leung, Koch, and $\mathrm{Lu}, 2002$ ). His second step was to empirically test the dual-motive model in three cultural contexts - Hong Kong, Beijing, and Australia (Leung, Brew, Zhang, and Zhang, 2011). His third step was to integrate his dual-motive model of harmony with the Western dual-concern model (Leung and Brew, 2009). Leung's dual-motive model was 'recently integrated with a major theoretical framework of interpersonal interaction from the West - the social exchange framework (Blau, 1964; Emerson, 1962; Homans, 1961)' (Leung, Wang, and Deng, 2016: 113).

\section{Conclusions}

From the experience of Leung's development of an indigenous dual-motive model of harmony and efforts to make it universal, we can see that it is entirely possible for Chinese management scholars to contribute indigenous ideas and theories to global knowledge. Leung's three-step integrative approach has proven useful for making contributions to global knowledge. Therefore, as Meyer (2006) encourages, Chinese management research needs more self-confidence.

Of course, to accomplish such a universalization process, one's self-confidence must be accompanied by intelligence and diligence. In this sense, Kwok Leung is undoubtedly a role model for many of us to follow!

The main challenge is to test the model empirically to avoid building 'nice', comprehensive, universal models that do not enhance universal knowledge. In addition to this, the model needs to be refined accordingly. Future empirical studies are indeed needed to test the universality of the model. 


\section{Bio-data}

Xin Li is an Assistant Professor at the Copenhagen Business School, Denmark. Verner Worm is a Professor at the_Copenhagen Business School, Denmark. Peihong Xie is an associate professor at the Shanghai University of International Business and Economics, China, PRC. 


\section{References}

Atkinson, J. W. 1964. An Introduction to Motivation. Princeton, NJ: Van Nostrand.

Barkema, H. G., X. P. Chen, G. George, Y. Luo, and A. S. Tsui. 2015. "West Meets East: New Concepts and Theories." Academy of Management Journal 58(2): 460-479.

Barney, J. B., and S. Zhang. 2009. "The Future of Chinese Management Research: A Theory of Chinese Management versus a Chinese Theory of Management." Management and Organization Review 5(1): 15-28.

Blake, R. R. and J. S. Mouton, 1964. The Managerial Grid. Houston, TX: Gulf Row.

Blau, P. M. 1964. Exchange and Power in Social Life. New York: Wiley.

Brew, F. P. 2007. "Harmony and Controversy: The Yin and Yang of Conflict in East Asian and Western Cultures." In Casting the Individual in Societal and Cultural Contexts: Social and Societal Psychology for Asia and the Pacific, edited by J. H. Liu, C. Ward, A. Bernardo, M. Karasawa, and R. Fischer, 39-59. Seoul, South Korea: Kyoyook-Kwahak-Sa Publishing Company.

Cheng, B. S., A. C. Wang, and M. P. Huang, 2009. "The Road More Popular versus the Road Less Travelled: An 'Insider's' Perspective of Advancing Chinese Management Research.” Management and Organization Review 5(1): 91-105.

Child, J. 2009. "Context, Comparison, and Methodology in Chinese Management Research." Management and Organization Review 5(1): 57-73.

De Dreu, C. K., A. Evers, B. Beersma, E. S. Kluwer, and A. Nauta. 2001. "A Theory-Based Measure of Conflict Management Strategies in the Workplace." Journal of Organizational Behavior 22(6): 645-668.

Deutsch, M. 1949. “A Theory of Competition and Cooperation.” Human Relations 2(2): 129-151.

Deutsch, M. 1973. The Resolution of Conflict: Constructive and Destructive Processes. New Haven, CT: Yale University Press.

Deutsch, M. 2000. Cooperation and Competition. In The Handbook of Conflict Resolution: Theory and Practice, edited by M. Deutsch, and P. Coleman, 23-40. San Francisco: Jossey-Bass.

Emerson, R. M. 1962. "Power-Dependence Relations.” American Sociological Review 27(1): 31-41.

Fang, T. 2012. "Yin Yang: A New Perspective on Culture." Management and Organization Review 8(1): 25-50.

Filley, A. C. 1975. Interpersonal Conflict Resolution. Glenview, IL: Scott, Foresman.

Follett, M. P. 1940/1926. "Constructive Conflict.” In Dynamic Administration: The Collected Papers of Mary Parker Follett, edited by H. C. Metcalf, and L. Urwick, 30-49. New York: Harper \& Row [Reprinted from: H. C. Metcalf, ed. 1926. Scientific Foundations of Business Administration. Baltimore: The Williams and Wilkins Company].

Gladwin, T. N., and I. Walter. 1980. "How Multinationals Can Manage Social and Political Forces." Journal of Business Strategy 1(1): 54-68.

Homans, G. C. 1961. Social Behavior and Its Elementary Forms. New York: Harcourt, Brace and World. 
Towards an integrative framework of conflict-handling behaviour Submitted to APBR, 19 April 2017

Revised \& Resubmitted, 23 June 2017 Final revision, 11 July 2017

Horney, K. 1945. Our Inner Conflict: A Constructive Theory of Neurosis. New York: W. W. Norton.

Hwang, K.K. 1997-8. "Guanxi and Mientze: Conflict Resolution in Chinese Society.” Intercultural Communication Studies 12(1): 17-38.

Jing, R., and A. Van de Ven. 2014. "A Yin-Yang Model of Organizational Change: The Case of CBG." Management and Organization Review 10(1): 55-80.

Leung, K. 1987. "Some Determinants of Reactions to Procedural Models for Conflict Resolution: A Cross-National Study.” Journal of Personality and Social Psychology 53(5): 898-908.

Leung, K. 1988. “Some Determinants of Conflict Avoidance.” Journal of Cross-Cultural Psychology 19(1): 125-136.

Leung, K. 1996. “The Role of Harmony in Conflict Avoidance.” Paper presented at 50th Anniversary Conference of the Korean Psychological Association, Seoul.

Leung, K. 1997. "Negotiation and Reward Allocations across Cultures." In New Perspectives on International Industrial and Organizational Psychology, edited by P. C. Early, and M. Erez, 640-675. San Francisco, CA: New Lexington.

Leung, K. 2007. "The Glory and Tyranny of Citation Impact: An East Asian perspective." Academy of Management Journal 50(3): 510-513.

Leung, K. 2009. "Never the Twain Shall Meet? Integrating Chinese and Western Management Research." Management and Organization Review 5(1): 121-129.

Leung, K. 2012. "Indigenous Chinese Management Research: Like It or Not, We Need It.” Management and Organization Review 8(1): 1-5.

Leung, K., Y. Au, J. Fernandes-Dols, and S. Iwawaki. 1992. "Preference for Methods of Conflict Processing in two Collectivist Cultures." International Journal of Psychology 27(2): 195-209.

Leung, K. and M. H. Bond. 1984. "The Impact of Cultural Collectivism on Reward Allocation." Journal of Personality and Social psychology 47(4): 793-804.

Leung, K., and F. P. Brew. 2009. "A Cultural Analysis of Harmony and Conflict: Toward an Integrated Model of Conflict Styles." In Understanding Culture: Theory, Research and Application, edited by R.S. Wyer, C.-Y. Chiu, and Y.-Y. Hong, 411-428. New York: Psychology Press.

Leung, K., F. P. Brew, Z. X. Zhang, and Y. Zhang. 2011. "Harmony and Conflict: A Cross-Cultural Investigation in China and Australia." Journal of Cross-Cultural Psychology 42(5): 795-816.

Leung, K., P. T. Koch, and L. Lu. 2002. "A Dualistic Model of Harmony and Its Implications for Conflict Management in Asia.” Asia Pacific Journal of Management 19(2-3): 201-220.

Leung, K., J. Wang, and H. Deng. 2016. "How Can Indigenous Research Contribute to Universal Knowledge? An Illustration with Research on Interpersonal Harmony.” Japanese Psychological Research 58(1): 110-124.

Lewicki, R., B. Barry, and D. Saunders. 2016. Essentials of Negotiations. 6th ed. New York: McGraw Hill International Edition.

Lewin, A. Y. 2014. "Emerging Economies Open Unlimited Opportunities for Advancing Management and Organization Scholarship." Management and Organization Review 10(1): 15 . 
Li, P. P. 2012. "Toward an Integrative Framework of Indigenous Research: The Geocentric Implications of Yin-Yang Balance." Asia Pacific Journal of Management 29(4): 849-872.

Li, P. P., K. Leung, C. C. Chen, and J. D. Luo. 2012. "Indigenous Research on Chinese Management: What and How." Management and Organization Review 8(1): 7-24.

Li, X. 2014. "Can Yin-Yang Guide Chinese Indigenous Management Research?.” Management and Organization Review 10(1): 7-27.

Lin, D., J. Lu, P. P. Li, and X. Liu. 2015. "Balancing Formality and Informality in Business Exchanges as a Duality: A Comparative Case Study of Returnee and Local Entrepreneurs in China." Management and Organization Review 11(2): 315-342.

Marshak, R. J. 1993. "Lewin Meets Confucius: A Review of the OD Model of Change." Journal of Applied Behavioral Science 29(4): 393-415.

Mathews, J. A., and H. Tan, 2015. "Zhu Xi's Neo-Confucian School: An Organizational Studies Reading." Asian Business \& Management 14(3): 227-246.

Meyer, K. E. 2006. “Asian Management Research Needs More Self-Confidence.” Asia Pacific Journal of Management 23(2): 119-137.

Morris, M. W., K. Leung, D. Ames, and B. Lickel. 1999. "Views from Inside and Outside: Integrating Emic and Etic Insights about Culture and Justice Judgment." Academy of Management Review 24(4): 781-796.

Peng, M. W., Y. Li, and L. Tian. 2016. “Tian-Ren-He-Yi Strategy: An Eastern Perspective.” Asia Pacific Journal of Management 33(3): 695-722.

Pruitt, D. G. 1983. "Strategic Choice in Negotiation.” American Behavioral Scientist 27(2): 167194.

Rahim, M. A. 1983. “A Measure of Styles of Handling Interpersonal Conflict.” Academy of Management Journal 26(2): 368-376.

Rahim, A., and T. V. Bonoma. 1979. "Managing Organizational Conflict: A Model for Diagnosis and Intervention." Psychological reports 44(3c): 1323-1344.

Redding, G. 2017. "Letter to the Editor.” Management and Organization Review 13 (1): 199

Redding, G., and M. A. Witt. 2015. "Advancing Indigenous Management Theory: Executive Rationale as an Institutional Logic." Management and Organization Review 11(2): 179-203.

Rowley, C. (2016). "Article Commentary: Whither globalization and convergence? Asian examples and future research." Asia Pacific Business Review, London: Taylor and Francis, online, http://www.tandfonline.com/doi/full/10.1080/13602381.2016.1238602 (accessed, 2 March 2017).

Thomas, K.W. 1976. "Conflict and Conflict Management.” In Handbook of Industrial and Organizational Psychology, edited by M.D. Dunnette, 889-935. Chicago: Rand McNally.

Thomas, K. W. and R. H. Kilmann. 1974. The Thomas-Kilmann Conflict Mode Instrument. Tuxedo Park, NY: Xicom, Inc.

Van de Vliert, E., and M. C. Euwema. 1994. "Agreeableness and Activeness as Components of Conflict Behaviors.” Journal of Personality and Social Psychology 66(4): 674-687.

Vroom, V. H. 1964. Work and Motivation. New York: Wiley. 
Von Glinow, M. A., and M. B. Teagarden. 2009. "The Future of Chinese Management Research: Rigour and Relevance Redux." Management and Organization Review 5(1): 75-89.

Warner, M. (2104). Understanding Chinese Management: Past, Present and Future, London and New York, NY: Routledge.

Whetten, D. A. 2009. "An Examination of the Interface between Context and Theory Applied to the Study of Chinese Organizations." Management and Organization Review 5(1): 29-55.

Tsang, E. W. 2009. "Chinese Management Research at a Crossroads: Some Philosophical Considerations." Management and Organization Review 5(1): 131-143.

Tsui, A. S. 2004. "Contributing to Global Management Knowledge: A Case for High Quality Indigenous Research.” Asia Pacific Journal of Management 21(4): 491-513.

Tsui, A. S. 2009. "Editor's Introduction-Autonomy of Inquiry: Shaping the Future of Emerging Scientific Communities." Management and Organization Review 5(1): 1-14.

Zhang, Y., D. A. Waldman, Y. L. Han, and X. B. Li. 2015. "Paradoxical Leader Behaviors in People Management: Antecedents and Consequences." Academy of Management Journal 58(2): 538-566.

Zhao, S., and C. Jiang. 2009. "Learning by Doing: Emerging Paths of Chinese Management Research.” Management and Organization Review 5(1): 107-119. 
Figure 1. Eliminating the overlapped and impossible combinations of dual-concern and dualmotive models

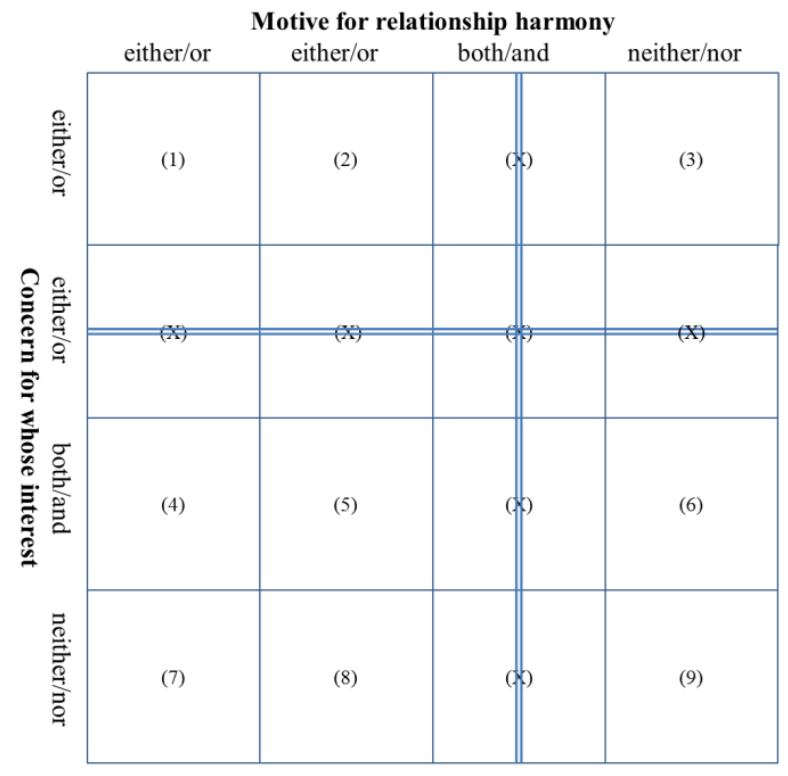

Figure 2. Our two-dimensional $3 \times 3$ integrative framework of conflict-handling behaviour

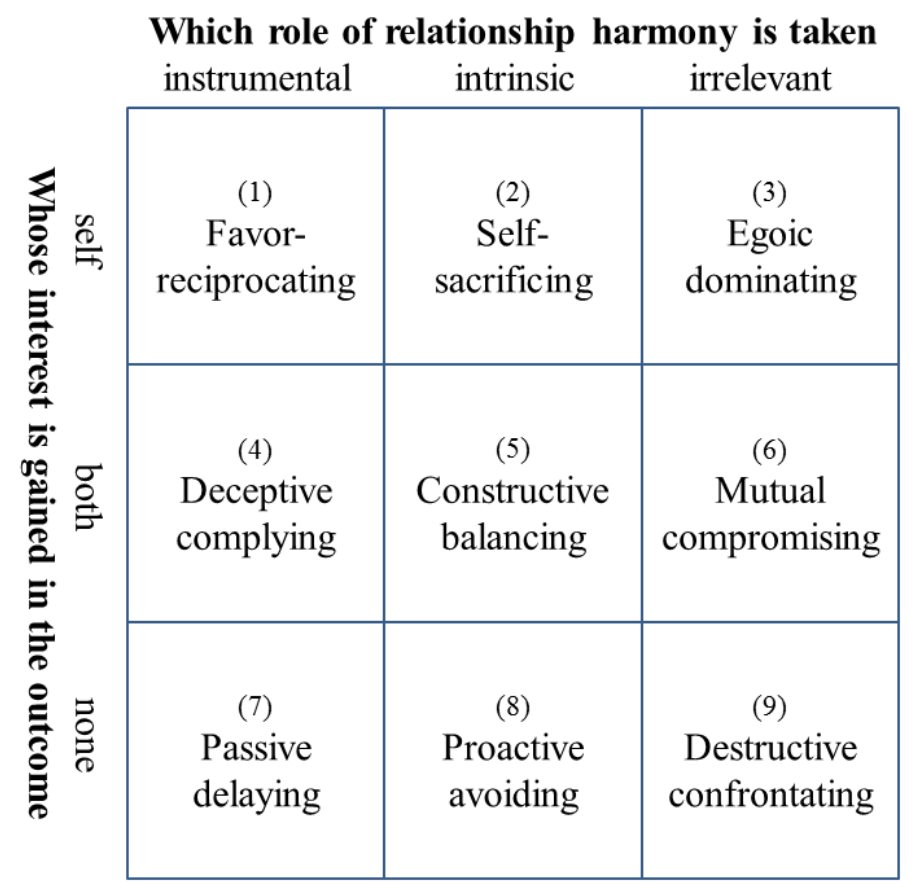

